\title{
Importance of Imaging Methods for Diagnosing Constrictive Pericarditis Versus Restrictive Cardiomyopathy
}

\author{
Importância dos Métodos de Imagem para o Diagnóstico de Pericardite Constritiva Versus Cardiomiopatia Restritiva
}

Débora Pereira Galvêas Negri ${ }^{1,2}$, Patrick Ventorim Costa ${ }^{1,2}$, Mateus Oliveira Potratz ${ }^{1,2}$, Carina Massariol
Belinassi',2, Fernando Luiz Torres Gomes ${ }^{1}$
${ }^{1}$ Cassiano Antônio de Moraes University Hospital, Federal University of Espírito Santo, Vitória, ES; ${ }^{2}$ Unimed Vitória Hospital, Vitória, ES, Brazil.

\section{Introduction}

Constrictive pericarditis $(\mathrm{CP})$ is a challenging differential diagnosis of chest pain in a cardiac emergency. This is the case report of a patient who presented with a seven-day history of chest pain for whom the possibility of calcified pericarditis was suggested due to changes on chest X-ray. After referral to a specialized cardiology service, transthoracic echocardiography (TTE) and cardiac magnetic resonance (CMR) showed that the case was compatible with $\mathrm{CP}$, which required surgical management. From chest $X$-ray to $C M R$, all imaging tests proved crucial for confirming the suspected diagnosis and defining the treatment.

\section{Case report}

A 41-year-old woman born in the state of Minas Gerais and living in Espírito Santo was transferred to the emergency room of a tertiary hospital with the complaint of a seven-day history of progressive and continuous stabbing retrosternal chest pain without irradiation. The patient denied dyspnea, but dyspnea on exertion began on the fifth day of the pain. She denied any previous comorbidities or the use of continuous medications. As a risk factor for cardiovascular diseases, she reported being a smoker (25 packs per year) and having a positive family history (her father had a stroke at age 60 years).

In the previous seven days, the patient had visited the health service four times and was released without a diagnosis upon receiving treatment for her symptoms. During emergency room visits, acute coronary syndrome was ruled out due to the absence of myocardial necrosis marker changes. In the last evaluation, changes compatible with pericardial calcification were noted on a chest X-ray (Figure 1) for which the patient was referred for specialist evaluation at a tertiary hospital. The patient was admitted with normal vital signs and cardiac and respiratory auscultation findings. The hypothesis of pericardial disease was raised after an evaluation of the complaint of chest pain refractory to the use of dipyrone and tramadol.

During the hospitalization, the patient underwent TTE to assess the clinical chest pain condition associated with the

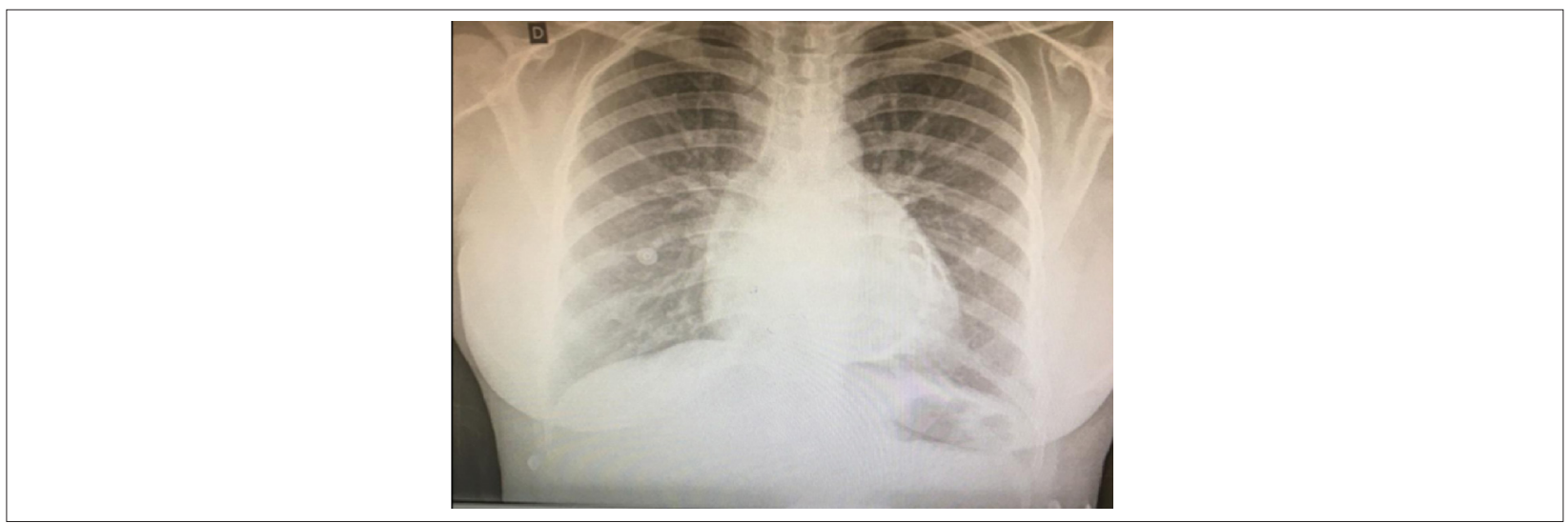

Figura 1 - Chest $X$-ray.

\section{Keywords}

Constrictive pericarditis; Echocardiography; Pericardium.

Mailing Address: Débora Pereira Galvêas Negri •

Hospital Universitário Cassiano Antônio de Moraes - Avenida Marechal

Campos, 1.355 - Santa Cecília - CEP: 29043-260 - Vitória, ES, Brazil.

E-mail: deboragalveas@hotmail.com

Manuscript received 4/29/2021; revised 8/27/2021; accepted 9/3/2021

DOI: 10.47593/2675-312X/20213404eabc213 
findings suggestive of pericardial calcification on the chest $X$-ray. The test showed biatrial enlargement (indexed left atrial volume, $37 \mathrm{~mL} / \mathrm{m}^{2}$; right atrial volume, $\left.36 \mathrm{~mL} / \mathrm{m}^{2}\right)$, respiratory transmitral flow variation (Figure 2 ) with an E/A ratio of 1.4 , a septal e' wave at a tissue Doppler of $14.1 \mathrm{~cm} / \mathrm{s}$, and a lateral $\mathrm{e}^{\prime}$ wave of $12.9 \mathrm{~cm} / \mathrm{s}$, findings suggestive of annulus reversus and marked anomalous septal bounce breathing (Video 1). The left ventricular ejection fraction was $69 \%$, but the longitudinal strain was reduced at $-15 \%$, with more negative values on the septal wall and fewer negative values on the lateral and anterior walls (possible wall movement restriction due to possible pericardial adhesion). The right ventricle (RV) showed dilation and contractile dysfunction $\left(S^{\prime} 8.7 \mathrm{~cm} / \mathrm{s}\right.$ ). The inferior vena cava was dilated with an estimated size of $2.3 \mathrm{~cm}$ and no respiratory variation. Analysis of the hepatic vein flow evidenced an end-expiratory retrograde/antegrade flow ratio of 1.04. Thus, the TTE findings corroborated the CP criteria (Table 1). At the time, no respirometer was available for the analysis.

In addition to the findings already described, the pericardium was apparently thickened with several hyperrefringent points related to the free RV wall and the inferolateral wall, with posterior acoustic shadowing suggestive of calcification.

CMR was performed to better define the anatomical calcification and plan the surgical approach by evaluating the best areas to be resected. We noted asynchronous septal bounce movement (Video 2), biatrial enlargement, RV systolic function at the lower limit with signs of external RV compression, and a pericardial thickness greater than $4 \mathrm{~mm}$.
A

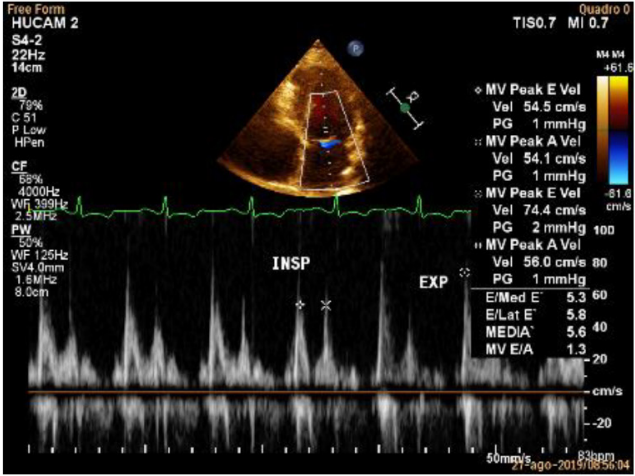

C

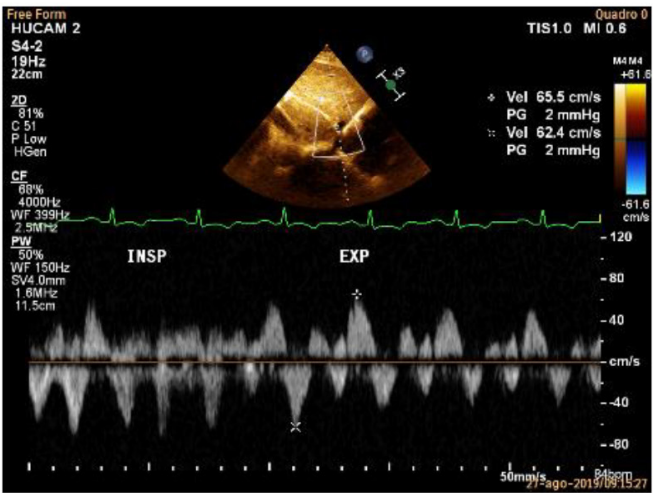

B

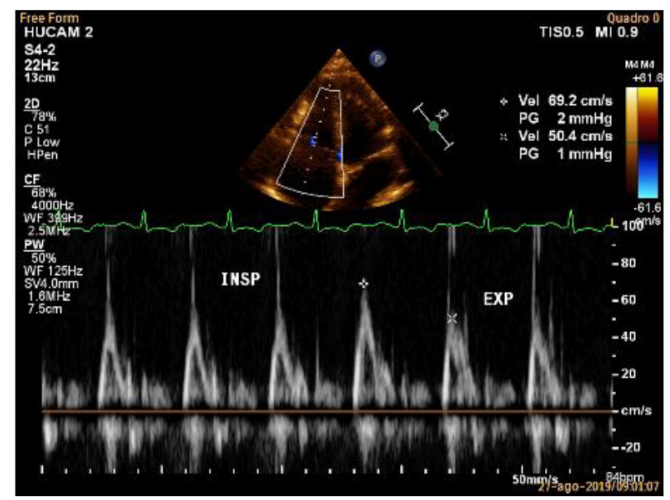

D
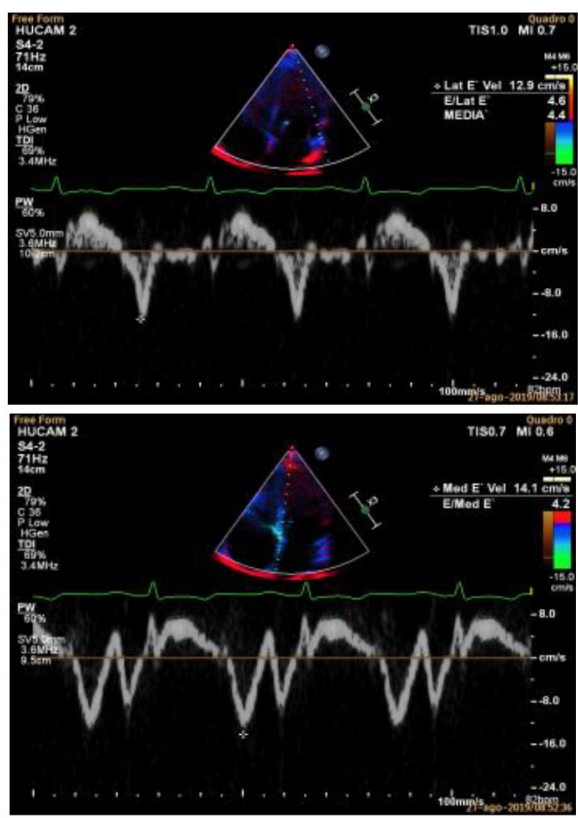

Figura 2 - Imagens pré pericardiectomia. (A) Variação respiratória do fluxo mitral de 37\%. (B) Variação respiratória do fluxotricúspide de - 38\%. (C) Relação do fluxo expiratório da veia hepática no final da diástole sobre o fluxo anterógrado > 0,8. (D) Velocidade de e' lateral de 12,9 cm/s e e' medial de $14,1 \mathrm{~cm} / \mathrm{s}$ (Annulus Reversus). 


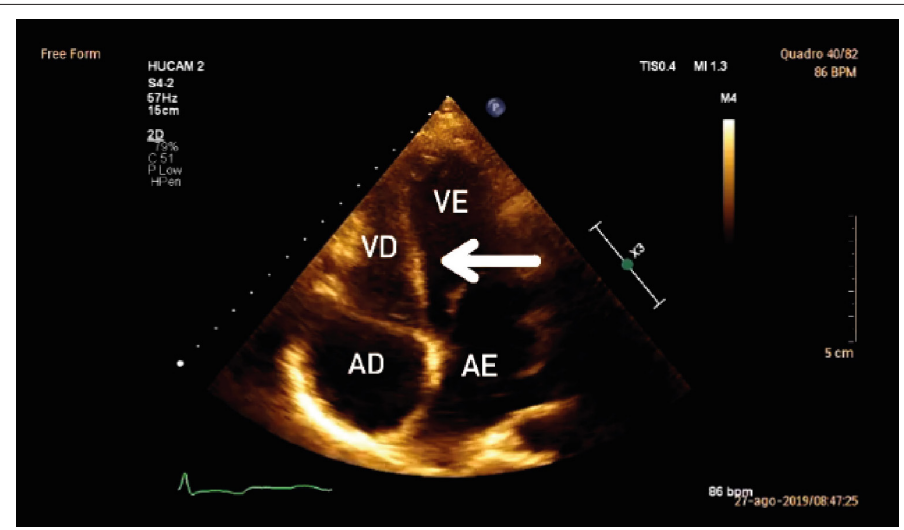

Vídeo 1 - Ecocardiograma transtoracico com movimentação anomala do septo interventricular (septal bounce).

Table 1 - Characteristics of constrictive pericarditis versus restrictive cardiomyopathy (included).

\begin{tabular}{|c|c|c|}
\hline & Constrictive pericarditis & Restrictive cardiomyopathy \\
\hline Pericardium & Abnormal & Normal \\
\hline Myocardium & Normal & Abnormal myocardial strain \\
\hline Atria & Normal or augmented & Augmented \\
\hline Septal bounce & Present & Absent \\
\hline Mitral valve on TTE & Transmitral flow velocity $>25 \%$ with respiratory variation & Normal mitral valve flow velocity \\
\hline Tissue Doppler on TTE & Normal diastolic relaxation & Reduced diastolic relaxation \\
\hline Annulus reversus on TTE & Present & Absent \\
\hline Global strain & Globally preserved with lateral reduction versus septal & $\begin{array}{l}\text { Globally decreased without significant regiona } \\
\text { heterogeneity }\end{array}$ \\
\hline
\end{tabular}

TTE: transthoracic echocardiography.

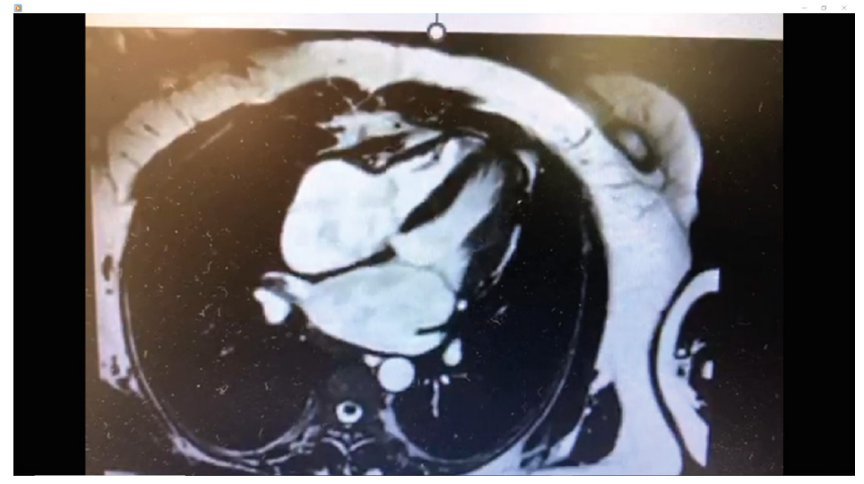

Vídeo 2 - Ressonancia magnética cardíaca com presença de septal bounce.

There was a high amount of calcium around the heart, especially in the posterior wall.

Laboratory tests were requested to investigate possible rheumatologic disease, but the results were negative. Due to the relationship between tuberculosis and calcified pericarditis, an investigation was conducted with the purified protein derivative tuberculin test, which was positive $(19 \mathrm{~mm})$.
During hospitalization, the patient's pain continued despite optimized analgesia. Her condition was resolved when she underwent pericardiectomy. The material extracted from the surgical procedure was referred for histopathological evaluation, which showed moderate chronic inflammatory infiltrate and chronic fibrosing inflammation with multiple foci showing dystrophic calcification. Due to the infectious 


\section{Case Report}

condition, the indicated postoperative tuberculous pericarditis treatment was rifampicin, isoniazid, pyrazinamide, and ethambutol associated with corticosteroids, and the treatment was completed after six months.

Unfortunately, echocardiograms performed about one month and one year after the pericardiectomy showed no reversal of the pericardial constriction pattern, a persistent prominent septal bounce, mitral and tricuspid respiratory variations, and annulus reversus. Strain values worsened compared to the initial values (-12.8\%) (demonstrated in Figure 3), which can be attributed to endocardial movement restriction, especially in the lateral LV wall, due to intense pericardial involvement in this area, although the patient presented no other episodes of chest pain, hospitalization, or complications and complained only of

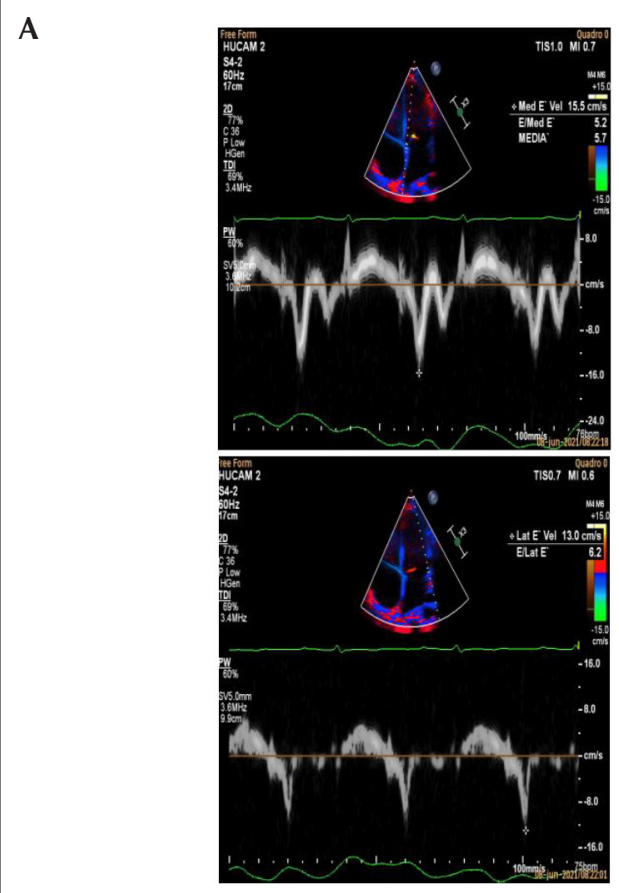

C

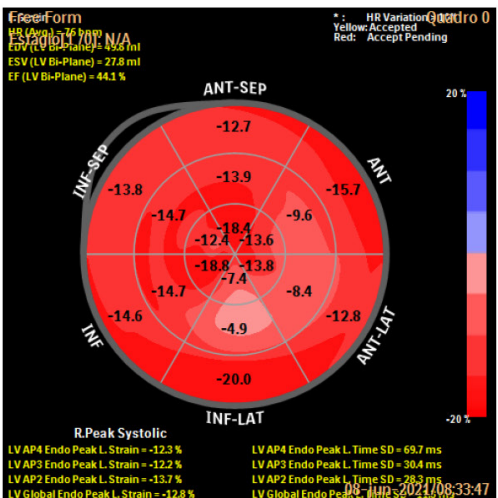

B
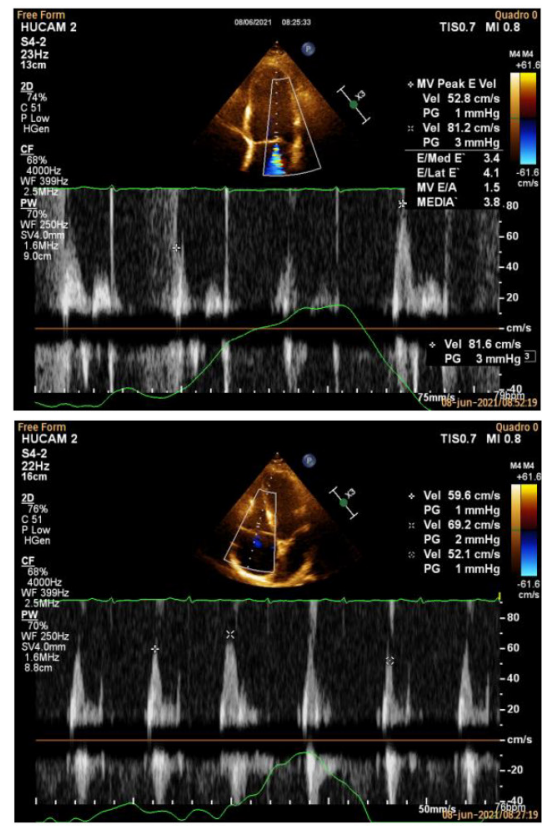

D
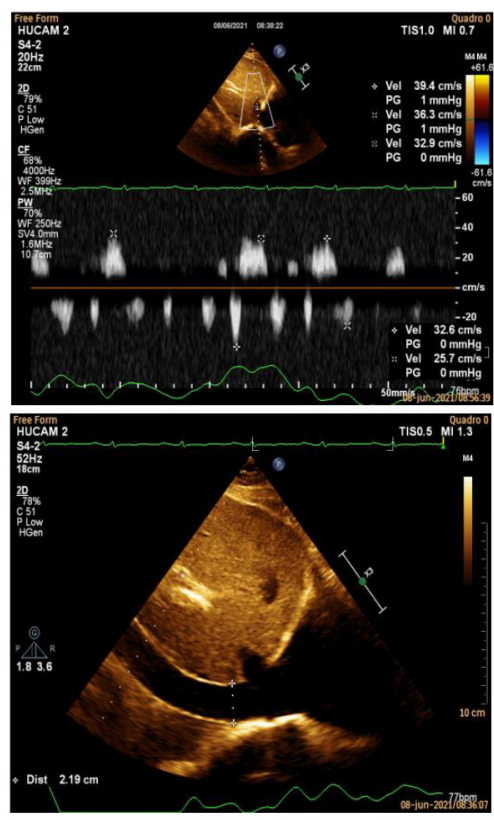

Figura 3 - Imagens pós pericardiectomia. (A) Manutenção do "Annulus Reversus". (B) Manutenção das variações respiratórias de $35 \%$ do fluxo mitral e -33\% do fluxo tricúspide. (C) Redução do strain longitudinal global, principalmente parede lateral. (D) Manutenção da relação do fluxo expiratório da veia hepática no final da diástole sobre o fluxo anterógrado > 0,8 e da dilatação da veia cava inferior. 
dyspnea on great exertion. Such sustained echocardiographic finding may occur in cases of pericardiectomy with incomplete pericardial resection.

\section{Discussion}

$\mathrm{CP}$ is pericardial hardening that impairs the diastolic filling of the ventricles with a subsequent increase in systemic venous pressures and a low cardiac output. It is generally a slow process that develops over three to 12 months and can occur after any pericardial disease process: viral infection, postcardiac surgery, post-radiotherapy, connective tissue diseases, other infections (tuberculosis or purulent pericarditis), or even more uncommon causes (malignancy, trauma, drug induction, asbestosis, sarcoidosis, or uremic pericarditis). ${ }^{1,2}$

$\mathrm{CP}$ rarely develops when acute pericarditis is adequately and effectively treated. Likewise, the drainage of pericardial effusions - particularly postoperatively - apparently reduced the likelihood of chronic CP. ${ }^{2}$

Clinically, the patient may present with right heart failure (HF), with a predominance of peripheral edema and anasarca. Chest pain complaints are present in only a small portion of patients. On physical examination, Kussmaul's sign, paradoxical pulse, and cardiac auscultation with pericardial knock (protodiastolic sound) are common findings. ${ }^{3,4}$

An electrocardiogram reveals no pathognomonic signs for the diagnosis. It is possible to find nonspecific S-T segment and $T$ wave changes. Chest $X$-ray findings are highly suggestive of $\mathrm{CP}$ when correlated with the clinical condition of right $\mathrm{HF}$ and signs of calcification around the heart. Also, CP due to tuberculosis has a high incidence of calcification. ${ }^{2,3}$

Pericardial calcification can occur in the absence of $\mathrm{CP}$, but it is usually less dense and irregularly distributed on an X-ray. It is important to differentiate $\mathrm{CP}$ from restrictive cardiomyopathy, as these conditions may present with similar clinical and hemodynamic findings but require different treatments. Thus, to define whether there is a constrictive pattern, additional imaging is needed. ${ }^{3}$

The echocardiogram is an important test used to define the CP pattern. Diagnostic findings include interventricular septum deviation that changes with breathing (septal bounce); diastolic flow reversal in the hepatic veins during expiration and normal or increased septal e' wave velocity on tissue Doppler (>8 cm/second). These three findings have a sensitivity of $87 \%$ and specificity of $91 \% .^{3-5}$ Other changes are respiratory

\section{References}

1. Lima MV, Cardoso JN, Cardoso CM, Brancalhão EC, Limaco RP, Barretto AC. Pericardite constritiva com calcificação extensa. Arq Bras Cardiol. 2011;96(1):e7-e10. doi: https://doi.org/10.1590/S0066782X2011000100018

2. Adler Y, Charron P, Imazio M, Badano L, Barón-Esquivias G, Bogaert J, et al.; ESC Scientific Document Group. 2015 ESC Guidelines for the diagnosis and management of pericardial diseases: The Task Force for the Diagnosis and Management of Pericardial Diseases of the European Society of Cardiology (ESC)Endorsed by: The European Association for Cardio-Thoracic Surgery (EACTS). Eur HeartJ. 2015;36(42):2921-64. doi: https://doi.org/10.1093/ eurheartj/ehv318 variations greater than $25 \%$ in mitral flow velocity and greater than $40 \%$ in tricuspid flow, polar strain map with greater sidewall, and reduced annulus reversus (transmitral $\mathrm{e}^{\prime}$ wave greater than lateral $\mathrm{e}^{\prime}$ wave)..$^{3-5}$

CMR is usually the method of choice after echocardiography for CP assessments. The diagnostic accuracy of magnetic resonance imaging (MRI) is greater than $90 \%$, but its main advantage is the ability to differentiate $\mathrm{CP}$ from restrictive cardiomyopathy. The presence of pericardial thickening $>4$ $\mathrm{mm}$ on MRI differentiates $\mathrm{CP}$ from restrictive cardiomyopathy with $88 \%$ sensitivity and $100 \%$ specificity. It also shows better anatomical definition of the calcification, which improves surgical planning in cases of pericardiectomy.

Other CMR findings are biatrial enlargement, dilatation of the inferior vena cava and hepatic vein, tubular-shaped ventricles, interventricular reversed septal curvature (RV diastolic dilatation sign related to its impaired filling), and the presence of pericardial delayed enhancement (post-contrast phase) suggestive of inflammation. ${ }^{3}$

After defining the diagnosis of $\mathrm{CP}$, it is essential to assess the disease stage to determine treatment. In initial cases without hemodynamic compromise but with early diagnosis, treatment can be based on the use of anti-inflammatory agents. In cases refractory to initial treatment, late diagnosis, or the presence of systemic symptoms with hemodynamic compromise, pericardiectomy is the indicated treatment. ${ }^{2,7}$

Finally, laboratory tests and electrocardiography have nonspecific CP findings. On the other hand, the findings of cardiac calcification on chest X-rays (easily available in emergency services) associated with signs of right HF can be considered a starting point for clinical suspicion. Complementary tests such as TTE and CMR are essential for differentiating between restrictive cardiomyopathy and $\mathrm{CP}$, making them important for its differential diagnosis, treatment, and prognosis. ${ }^{1,3}$

\section{Authors' contributions}

Research conception and design: Negri DPG, Costa PV, Potratz MO, Belinassi CM, and Gomes FLT.

\section{Conflict of interest}

The authors have declared that they have no conflict of interest.

3. Fadl SA, Nasrullah A, Harris A, Edwards R, Kicska G. Comprehensive review of pericardial diseases using different imaging modalities. Int J Cardiovasc Imaging. 2020;36(5):947-69. doi: https://doi.org/10.1007/s10554-020-01784-x

4. Welch TD. Constrictive pericarditis: diagnosis, management and clinical outcomes. Heart. 2018;104(9):725-31. doi: 10.1136/ heartjnl-2017-311683

5. Masui T, Finck S, Higgins CB. Constrictive pericarditis and restrictive cardiomyopathy: evaluation with MR imaging. Radiology. 1992;182(2):369-73. doi: 10.1148/radiology.182.2.1732952

6. Klein AL, Abbara S, Agler DA, Appleton CP, Asher CR, Hoit B, et al. 


\section{Case Report}

American Society of Echocardiography clinical recommendations for multimodality cardiovascular imaging of patients with pericardial disease: endorsed by the Society for Cardiovascular Magnetic Resonance and Society of Cardiovascular Computed Tomography. J Am Soc Echocardiogr. 2013;26(9):965-1012.e15. doi: 10.1016/j.echo.2013.06.023
7. Bertog SC, Thambidorai SK, Parakh K, Schoenhagen P, Ozduran V, Houghtaling PL, et al. Constrictive pericarditis: etiology and cause-specific survival after pericardiectomy. J Am Coll Cardiol. 2004;43(8):1445-52. doi: 10.1016/j.jacc.2003.11.048. 